\title{
Adaptable buildings for sustainable built environment
}

\section{Purpose}

The purpose of this paper is to explore the ability of 'adaptable buildings' to respond to future potential built environment changes in sustainable way.

\section{Design/methodology/approach}

A detailed literature review and a case study were undertaken to identify the life cycle changes of typical buildings over a period of more than 100 years. Twelve (12) semistructured interviews were conducted among construction industry professionals to identify how adaptable buildings enhance sustainability within the built environment. Case study data were analysed through a Morphological Analysis, and the interview data were analysed through discourse analysis.

\section{Findings}

Out of the many adaptable features, the results revealed 'change of use' as the dominant trend within the buildings of the selected urban cluster. More than $60 \%$ of buildings have changed their original use during their lifecycle. Around $10 \%$ of them have changed their use frequently (every 6 year) during the last 20 years thereby signalling an increase in the rate of change. The positive contribution of adaptable buildings in achieving sustainability in terms of economic, social and environmental considerations, were confirmed through the analysis of semi-structured interviews.

\section{Originality/value}

This paper reports a longitudinal study spanning over 100 years, exploring the extent of building adaptation within a selected cluster of Liverpool city centre, UK. The study further confirms the need to incorporate adaptability as a key criterion when designing buildings. The increased rate at which 'change of use' has occurred further reinforces the need. Lack of track records on designing for reuse makes this an interesting challenge for the construction industry, hence likely to have significant implications for policy / strategy formulation.

Keywords:

Built environment challenges, adaptable buildings, change of use, sustainability

\section{Paper type: Research paper}




\section{Introduction}

Challenges within the built environment are identified in the areas of 'environment considerations' (Kincaid, 2000; Geraedts, 2008), 'innovations in technology' (Flanagan and Tate, 1997; Nutt, 2000), 'planning and policy issues', 'social requirements', 'political forces' (Gann and Barlow, 1996) and 'economic considerations' (Arge, 2005; Douglas, 2006). To respond to these macro level challenges, buildings need to be changed in terms of the 'function' they house, the 'capacity' to achieve the performance required for the population they hold and the 'flow' of reacting to internal and external environmental forces (Slaughter, 2000). These challenges occur often unpredictably and without regularity (Latham, 2000). Buildings which are unable to adapt with such challenges will become prematurely obsolete or require substantial refurbishment or demolition, where neither option may create a sustainable built environment.

Existing building stock is an important physical, economic, social and cultural capital to any nation (Kohler and Hassler, 2002). Building obsolescence/redundancy is identified as one of critical issues associated within the existing building stock. To minimise such negative impacts created through building redundancy, strategies such as 'adaptive reuse' (Kincaid, 2000), 'creative reuse' (Latham, 2000) and 'brownfield developments' (Silverthorne, 2006) have been promoted as better means for reusing the existing buildings. In a way, benefits of reuse are seen as not only a low cost option for the typical end-user, but also in the value of retaining the style and character/heritage of buildings (Ball, 1999). However, this preparation lies in a carefully considered response to the building's structure, elements and components (Latham, 2000).

The UK government legislation (e.g. landfill tax) and policies (e.g. Strategy for Sustainable Construction, 2008; Construction 2025, 2013) promote sustainable buildings. This encourage owners/clients and developers to rethink the possibilities and potential avenues for adaptive reuse within their current and proposed buildings. In addition, the government is seeking alternative strategies to minimise building redundancy while promoting optimum use of the existing building stock in urban centres, rather than demolition and renewal (Davison et al., 2006). Nevertheless, the conversion processes of traditional mal-adaptive buildings might be neither economical nor practical in many circumstances. Shipley, Utz and Parsons (2006) noted that an average of $10 \%-12 \%$ cost savings can be expected from adaptive reuse over building a new. Therefore, consideration has been given to identify how the new building stock can be adapted for the future changes (Henehan and Woodson, 2003; Sheffer and Levitt, 2010) and opportunities for existing building stock to sustain in the future potential markets. 
Adaptable buildings are widely recognised as intrinsic to a sustainable built environment (Kendall and Ando, 2005) as they focus on bespoke solutions which, wherever possible, are flexible to varying stakeholder needs. This paper explores how adaptable buildings respond to the life cycle changes of buildings while enhancing sustainability. Firstly, the paper identifies the life cycle changes of typical buildings and supporting infrastructure through a case study. The findings of this case study confirm that a significant number of buildings demand change of use during their life cycles, and there is an urgent need to explore practical and sustainable solutions to respond to these challenges. Secondly, the findings of the literature review are presented. This review elaborates the principles, strategies and parameters for designing adaptable buildings. Thirdly, findings from the interviews emphasising the role of adaptable buildings towards achieving sustainability are presented. Finally, overall conclusions and implications of this study are highlighted and further research directions are suggested.

\section{Research methods}

A detailed literature review was undertaken to identify the principles, design strategies and parameters for adaptability in buildings. A case study was undertaken within a city centre in the North West of England, UK, to explore how the buildings and its supporting infrastructure have changed over period of 100 years. Historic maps and building data were collected from Liverpool public library and the space use pattern were analysed through a Morphological Analysis. In addition twelve (12) semi-structured interviews were conducted among the construction industry professionals to review the capability of adaptable buildings to respond to the life cycle changes of buildings, and also to learn how they enhance sustainability. The selected interviewees were from architecture, quantity surveying, construction management and project management disciplines. Their industry involvement varied from less than 10 years to more than 30 years, thereby demonstrating a good spread of professional experience. Interview data were analysed through Discourse Analysis. The outcomes derived from the case study and interview analysis were re-examined with the literature review.

\section{The case study}

The selected case study was based within a relatively larger geographical area within the city of Liverpool, UK. It was used to identify the typical changes related to buildings and its infrastructure over a period of more than 100 years. Liverpool is a large city in the North West of England. It has regenerated immensely as a city in recent years and has undergone 
significant economic restructuring and urban change over the last 40 years (Couch, 2003). In general, a conversion of aged historic buildings to new uses, an upgrade to a same use, remained as vacant or demolition (if permitted) is quite common within the current building stock. Liverpool city accommodates a significant number of historic buildings that are classed as "listed buildings" by the local authority. As demolition is rarely permitted, the owners of such buildings are compelled to consider the adaptable potentials from a historic (time value) and / or heritage (significance) point of view. The findings of this case study elaborate how the city has transformed by describing its change over time and by identifying the principles of planning and practices in rebuilding, that can promote social, economic and environmental vitality.

Both historic and current maps for the years 1890, 1924, 1988, 2004, 2010, 2015 were used to study the pattern of functional transformations of buildings over the last 100 years. Five (5) main uses of buildings were identified, namely, residential, commercial, industrial, social and leisure categories. Residential category included detached, semi-detached, terraced houses and apartment blocks. Commercial comprised offices, banks, public houses, hotels and retail categories. Industrial included buildings for manufacturing and warehouses. Social category covered schools, churches, clubs, hospitals and buildings which were built for community wellbeing. Leisure included theatres, parks and other recreational facilities. A combination of two or more different uses was categorised under mixed-use category.

The selected cluster from the historic maps of Liverpool is a triangular shaped area located at the commercial hub of the Liverpool city centre. It is bounded by Church Street to the top, Hanover Street to the right and Paradise Street to the left. The main reason for selecting this particular cluster was its' representation of all the functional units better than the other possible clusters. Moreover, two direct observations were undertaken within the selected cluster to confirm the most recent changes made in to the buildings as there were several ongoing refurbishments during 2010 - 2015. The changes appeared mainly in building functions, and its physical settings (size, shape, location etc.). On average, less than $12 \%$ of buildings in the selected cluster have changed physically (horizontal and vertical extensions; relocation and replacements). However, the limited access to individual building data influenced this study into investigating the functional changes of buildings over their life cycles. Therefore, building change of use patterns were studied within the selected cluster. The variation of building use was highlighted on the location maps by assigning the different colours to each functional unit. 


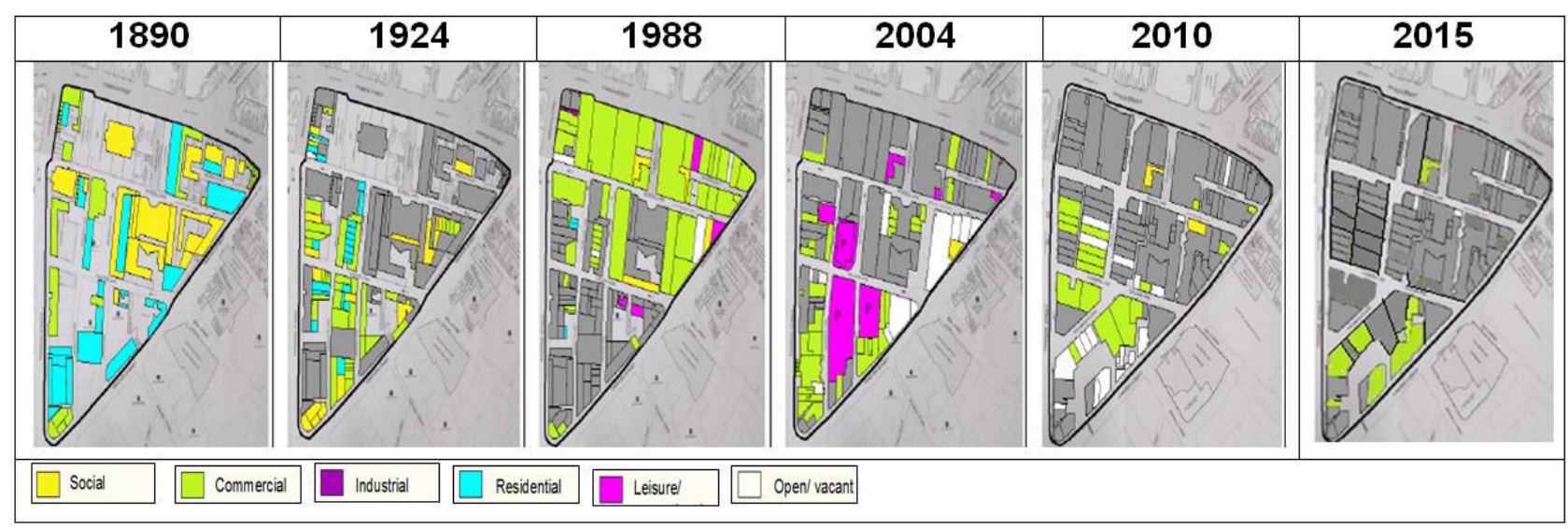

Figure 1 - Building change of use over a period of 100 year life span

The colours; yellow: social, light green: commercial, sky blue: residential, purple: industrial, pink: leisure and recreational, grey: buildings with no change of use, and white: open/vacant spaces were assigned to represent the change of use in buildings with comparison to their previous use. No mixed-use facilities were identified within the cluster. The land area taken by particular buildings in the selected cluster were measured using AutoCAD software. The percentage of functional transition of space were measured during the $1890-1924,1924-$ 1988, 1988 - 2004, 2004 - 2010, 2010 - 2015 time periods as illustrated in Table 1.

Table 1 - Percentage of functional transition of buildings

\begin{tabular}{|l|c|c|c|c|c|}
\hline $\begin{array}{l}\text { Functional } \\
\text { transition }\end{array}$ & $1890-\mathbf{1 9 2 4}$ & $\mathbf{1 9 2 4 - 1 9 8 8}$ & $\mathbf{1 9 8 8 - 2 0 0 4}$ & $\mathbf{2 0 0 4 - 2 0 1 0}$ & $\mathbf{2 0 1 0} \mathbf{- 2 0 1 5}$ \\
\hline Commercial & $+14 \%$ & $+67 \%$ & $+16 \%$ & $+13 \%$ & $+9 \%$ \\
\hline $\begin{array}{l}\text { Leisure and } \\
\text { recreational }\end{array}$ & - & $+6 \%$ & $+38 \%$ & $-26 \%$ & - \\
\hline Social & $+8 \%$ & $+5 \%$ & $-11 \%$ & $+2 \%$ & - \\
\hline Residential & $+7 \%$ & $-18 \%$ & - & - & - \\
\hline Vacant & - & $+2 \%$ & $+13 \%$ & $+12 \%$ & $\begin{array}{c}\text { Less than } \\
1 \%\end{array}$ \\
\hline
\end{tabular}

The two symbols '+' and '-' represent the percentage increase and decrease of the space accommodated by particular use/function respectively. The 1890 map shows the Church of England and its graveyard, a theatre, a club and a hotel along Church Street. Bluecoat school (also referred to as Bluecoat hospital) was located at the centre of the cluster. A few public houses (pubs) were located along the Hanover and Paradise Streets. Residential houses were scattered everywhere within the cluster. The cluster accommodated social and commercial facilities. This represents the vibrant socio-economic status that the city was renowned for during this period as a globally known port city. The Bluecoat school was moved away from the cluster in 1906, and the space was used to accommodate Bluecoat art 
gallery and the museum. In 1923 the cathedral was demolished and graveyard was removed to the outskirts of Liverpool. A new building was built on the same site and was used for clothing retail (Woolworths and HMV). In 1966 the city corporation (now city council) demolished 78,000 houses - effectively most of the residential heart of the city (Latham 2000 cited Barnard 1970). This was noticed in the selected cluster as $18 \%$ decline in residential facilities during the period of 1924-1988.

The cluster began to commercialize after the Second World War, adding growing employment opportunities for the people in Liverpool. As a result, the town economically and socially stabilized. In the1988 map, two banks (Barclays, Lloyds), Boots chemist, retailers of clothing (Dorothy Perkins, Littlewoods, Burton, C\&A clothing etc.) had been added to the cluster. Bluecoat art gallery remained at the same location. Liverpool One Paradise street development, a four year development programme (2004 - 2008), was the largest city centre regeneration scheme in Europe at the time (Daramola-Martin, 2009). It changed the face of town centre, and brought lots of people into the city. A continuous increase in vacant spaces was identified during the period of $1924-2010$.

Demolition of few of those vacant buildings was also noted on the 1988 map. During this period a partial renovation was undertaken inside the Bluecoat gallery and the internal space was divided to accommodate restaurant, office and a cafeteria. Next (a clothing retailer) was moved into the C\&A clothing premises. The 2004 map showed more parking spaces. Presumably this reflects the attractiveness of the particular cluster as people tended to come to the city for social, commercial and leisure purposes. Having identified the growing commercial value of particular cluster, the recreational facilities were replaced with commercial facilities in 2010. In 2010 map, there were no remarkable changes to the existing commercial facilities of the cluster except Littlewoods retail was shifted away and the building space was occupied by Primark clothing. Few vacant buildings (approximately 12\%) could be identified within the 2010 map. It is worth highlighting that in the 2015 map, such vacant spaces have reduced to a less than $1 \%$, and the commercial building spaces have increased up to $9 \%$. This provides evidence that many redundant buildings identified in the 2010 map have begun to function as commercial facilities by 2015 , thereby indicating the economic development of the city.

Although an impact from the 2008 economic crisis was remarked, it could be assumed the impact was lessened by Liverpool being selected as World Heritage Site by the UNESCO (United Nation's Educational Scientific and Cultural Organisation) in 2004, which encouraged the city to grow and expand, while achieving a careful balance between conservation and regeneration, creating modern heritage and ensuring that 'the future is built upon the past'. 
Moreover, the city was awarded the European capital of culture in 2008, and a regenerationled boost in Grosvenor's (private sector developer) £1 billion commitment (Daramola-Martin, 2009) provided considerable funding to the redevelopment of Liverpool city centre.

Having analysed the causes for building change of use within the selected cluster, it was identified that a majority of them were influenced by the government planning and policy decisions.

The findings of this case study confirmed that around $60 \%-70 \%$ of the buildings of the selected cluster have changed their original use/function during some point in their lifecycle. However, there was no robust data to prove the impact and magnitude of those alterations. The results further evidenced that $10 \%-12 \%$ of buildings in the selected cluster had changed their original use every 6 years over the period of last 25 years. Therefore, the real need is to explore the possibilities to integrate the 'potential to adapt' in future buildings.

\section{Role of adaptable buildings}

The importance of 'adaptable buildings' has been frequently discussed in literature, particularly with regard to various facets of building adaptations, such as technical and functional performance of adaptable buildings' (Gann and Barlow, 1996; Slaughter, 2001; Kendall, 2003; Larssen and Bjorbery, 2004), 'stakeholders' motivation and benefits' (Arge, 2005; Kalita, 2006), 'regulations and policies' (Kincaid, 2002; Adeyeye, Bouchlaghem and Pasquire, 2010; Ren, Shih, and McKercher, 2014), 'sustainability' (Kincaid, 2000, Thomsen and Flier, 2009) and 'risk' (Remoy and Voordt, 2007). Adaptable buildings are defined as 'dynamic systems that carry the capacity to accommodate a set of evolving demands regarding space, function, and components' (Adaptable Futures, 2012). A maladaptive building is one that cannot match the new demands placed upon it, due to being technically non-viable or cost-inefficient. The line between the two can often become unclear and depends on a set of exogenous and endogenous demands that can be determined through careful evaluation. Correspondingly, open building design (Habraken, 1980; Kendall, 1999) provides a similar conceptual philosophy but falls short of providing clear criteria for evaluation, focusing primarily on the separation of long and short-term components. Literature reveals adaptable buildings as an emerging but strong and practical solution to defeating the problem of building redundancy (Douglas, 2006; Kronenburg, 2007; Adaptable Futures, 2012). However, the critical challenge to building stakeholders, who have different interests and influence over the project, is the inability to prepare for unforeseeable futures, mainly because of the difficulty in predicting future uncertainties, risks and the costs of change (Ellingham and Fawcett, 2006). 


\section{Strategies and design parameters for adaptability in buildings}

A variety of adaptable strategies are discussed in the recent literature. Among these strategies, 'adaptability' and 'flexibility' are often used to convey a similar meaning. 'Adaptability' is used to explain macro level issues such as 'capability of social uses', and 'flexibility' is used to address micro level issues such as 'capability of physical changes' (Groak, 1992). By contrast, Schneider and Till (2005) define 'flexibility' as a common term to represent the capability of buildings to accept both different social uses and physical arrangements. Beisi (1993) argued that providing adaptability is not a one-time strategy but should guarantee the long-term possibilities of use.

Table 2 - Design strategies for adaptability

\begin{tabular}{|c|c|c|c|c|c|c|c|c|c|c|c|}
\hline Design Strategies & 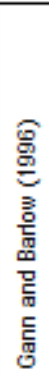 & 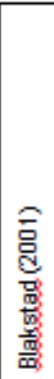 & 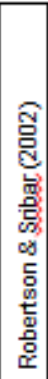 & \%ิ & 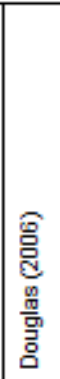 & 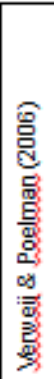 & 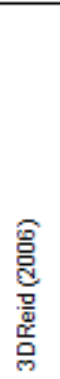 & 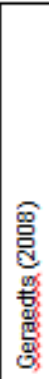 & 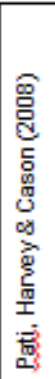 & 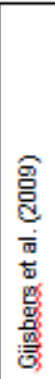 & 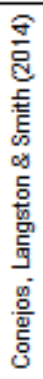 \\
\hline Generality & & & & $\bullet$ & & & & & & & \\
\hline Flexibility Nersatility & & - & & - & - & & • & - & - & - & - \\
\hline $\begin{array}{l}\text { Elasticity/Extendable/ } \\
\text { Expandable/Scalable }\end{array}$ & & • & • & • & $\bullet$ & • & $\bullet$ & - & • & & \\
\hline Convertible & & & & & $\bullet$ & & $\bullet$ & & - & & \\
\hline $\begin{array}{l}\text { Dismantlable/ } \\
\text { Separable/ Partitionable }\end{array}$ & & • & - & & $\bullet$ & & & • & & • & - \\
\hline Disaggregatable & & & & & • & & & & & & \\
\hline $\begin{array}{l}\text { Prefabrication/ } \\
\text { Standardisation }\end{array}$ & $\bullet$ & & & & & & & & & $\bullet$ & \\
\hline Overcapacity & - & & & & & & & & & & \\
\hline Movable & - & & & & & & $\bullet$ & $\bullet$ & & $\bullet$ & \\
\hline Rearrangeable & $\bullet$ & & & & & & & - & & & \\
\hline Reusable/Recyclable & & & $\bullet$ & & & & $\bullet$ & & & & \\
\hline Refitable & & & & & & & $\bullet$ & & & & \\
\hline Multi-functional & & $\bullet$ & & & & & & & & & \\
\hline Integratable & & & - & & & & & & & & \\
\hline Universal & & & & & & & & - & & & \\
\hline Modularity & & & & $\bullet$ & & & & & & & \\
\hline Ejectable & & & & & & & & $\bullet$ & & & \\
\hline Exchangeable & & & & & & & & - & & & \\
\hline
\end{tabular}

The strategies of durability and design for disassembly are closely related to adaptability, which in different forms enhance long-term environmental performance (Russell and Moffatt, 2001). The term 'convertible' determines the ability of buildings to shift between different 
use/function, which is the main focus of this paper. Integration of these strategies within new buildings can 'effectively reduce life cycle costs by allowing a timelier and less costly response to a dynamic environment, which adds costs measured in terms of money, time, and complexity' (Ford and Garvin, 2010 p.54). Considerations are given to manage the simplicity and legibility of building, multifunctional spaces, excess service capacity of buildings to facilitate future potential uses. However, semantic permutations/dependencies between some of the above strategies create difficulties in clustering them into specific individual categories. Having introduced shearing layers of building change, Brand (1994) stated that buildings are not just static objects but that they are dynamic and tears itself over time. Hence, designing a building to adapt to a potential change of use means allowing its hierarchical layers to change; each in its own time scale. However, there are critical design parameters (see Table 3 ) that need to be considered when designing buildings towards potential adaptation.

Table 3 - Design parameters for adaptability in buildings

\begin{tabular}{|c|c|c|c|c|c|c|c|c|c|c|c|c|c|c|c|c|c|c|c|c|c|c|c|c|c|c|c|c|c|c|c|c|c|}
\hline \multirow[b]{2}{*}{ Authors } & \multicolumn{33}{|c|}{ Design parameters for adaptability in buildings } \\
\hline & 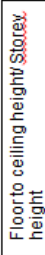 & 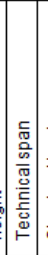 & 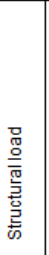 & 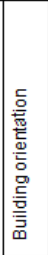 & 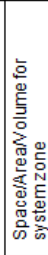 & 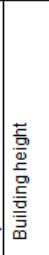 & 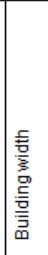 & 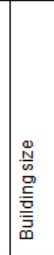 & 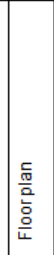 & 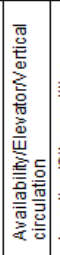 & 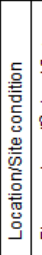 & 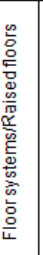 & 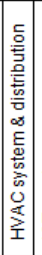 & & 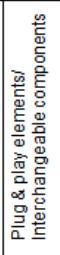 & 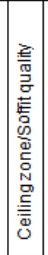 & 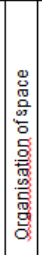 & 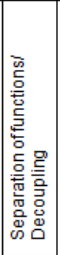 & 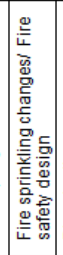 & 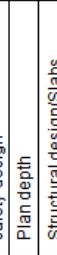 & 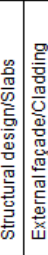 & 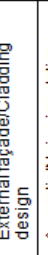 & 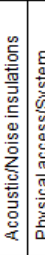 & 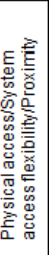 & 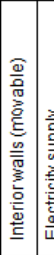 & 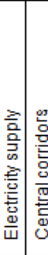 & 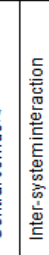 & 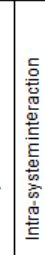 & 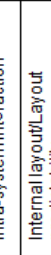 & 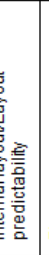 & 言 & 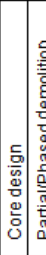 & 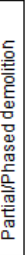 \\
\hline Gann and Barlow (1996) & & & & & & - & $\bullet$ & & & & & & - & & & & & & $\cdot$ & $\cdot \cdot$ & $\cdot$ & - & - & • & & & & & & • & & & \\
\hline Ratcliffe and Stubbs (1996) & - & & & & & & & & & & & & & & & & & & & & & & & & & & & & & & & & \\
\hline Kexmer (2000) & & & & & • & & & & & & & & & & • & & & & & & & & & • & & & • & • & & • & $\cdot$ & $\cdot \cdot \cdot$ & \\
\hline Heath (2001) & - & & & & & & & & & & & & & & & & & & & $\cdot \cdot \cdot$ & • & & & & & $\cdot$ & & & & & & & \\
\hline Larssen and Bjorberg (2004) & • & $\cdot$ & - & & $\cdot$ & & & & & $\cdot$ & $\bullet$ & & $\cdot$ & - & & & & & & & $\cdot$ & & & & $\cdot \cdot$ & • & & & & & & & \\
\hline Arge (2005) & - & $\bullet$ & & & & & - & & & & & - & - & • & • & - & - & • & • & & & & & & & & & & & & & & \\
\hline Richter and Laubach (2005) & & & & & & & & & & & & $\cdot$ & • & & & & & & $\cdot$ & & - & - & & - & & & & & & & & & \\
\hline Verweij and Poelman (2006) & & & & & & & & • & - & & & & & & & & & & & & & & & & & & & & & & & & \\
\hline 3DReid (2006) & - & & & & & & & & & • & & - & & & & $\cdot$ & & & • & $\cdot \bullet \cdot$ & - & • & & • & & & & & & & & & \\
\hline Gijsbers et al. (2009) & • & & & & • & & & & & & - & & & • & & & & • & & & & & & • & • & & • & & & & & & \\
\hline Rawlinson and Harrison (2009) & $\bullet$ & $\cdot$ & & • & & & • & & & $\cdot$ & & & $\cdot$ & & & $\cdot$ & & & & $\cdot \bullet$ & $\cdot$ & & & • & & & & & & & & & \\
\hline Wilkinson (2014) & $\cdot$ & • & & & & & & & • & & & & & & & & & & & & & & & & & & & & & & & & \\
\hline & 8 & \begin{tabular}{|l|} 
\\
\end{tabular} & 1 & 1 & 3 & 1 & 3 & 1 & 2 & \begin{tabular}{l|l}
3 \\
\end{tabular} & \begin{tabular}{|l|}
2 \\
\end{tabular} & 3 & \begin{tabular}{|l|}
5 \\
\end{tabular} & 3 & 2 & 3 & 1 & 2 & \begin{tabular}{l|l}
4 \\
\end{tabular} & \begin{tabular}{|l|l|l|}
4 & 6 \\
\end{tabular} & 6 & \begin{tabular}{l|l}
3 & \\
\end{tabular} & 1 & 6 & \begin{tabular}{|l|}
2 \\
\end{tabular} & \begin{tabular}{l|l}
1 & 1 \\
\end{tabular} & 2 & & 1 & 2 & & \begin{tabular}{|l|l}
1 & \\
\end{tabular} & \\
\hline
\end{tabular}

One or more of the above-mentioned design parameters influence the buildings when designing for future adaptation. From the case study described above, it was also noted that 'floor to ceiling height / storey height' is one of critical parameters that highly influenced when undertaking building conversions. Buildings with higher floor to ceiling heights are easily capable of accommodating new uses. Supportively, Farrell, $(1979$, p.59) stated that the inherent flexibility of many of the Georgian and Victorian domestic buildings has been very influential in the development of ideas of adaptability in new work, especially housing and industrial buildings'. Moreover, Gregory (2006) noted that the buildings best suited to adaptation are those with the most generous ceiling heights. However, 'too much floor to 
floor clearance is wasteful in the long term and also in the short term; too little is always wasteful in the long term as use changes, and in the short term hostile to energy use and people' (Kincaid, 2000, p.158). In addition, Saari and Heikkila (2008, p.240) explain that the 'long-term adaptability of old industrial properties has been particularly good thanks to high floor heights and long spans and their conversion to office and residential use has been possible and relevant in several recent construction projects'. Kaputsyan (1974, p.280) also noted storey height as a significant economic parameter whilst emphasising that the 'economic level of mass-scale housing construction for a specific period is stimulated by the standard requirements, thus formulating such economic parameters as the upper limits of the floor space of flats, the height of a storey, the number of lifts and the like'. Lau (2001) identified 'floor height/storey height' as one of the marketable factors that clients/owners most often consider when buying or leasing a space. However, rigid planning regulations confine the designers to act within the stipulated height restrictions, thereby limiting the potential adaptation. In fact, although there are buildings with adaptable features; it is unclear whether they fully match with the performance of purpose-built buildings with regard to layout and height restrictions (Douglas, 2006). The literature identified 'adaptable building' as a more established notion for designing buildings for future change of use. However, it is essential to consider its contribution to sustainability, due to the fact that sustainable practices are now a primary concern in global agendas and of the UK Government strategies.

\section{Contribution towards sustainability}

Sustainability is a major criterion when evaluating buildings and their associated components. If a building is to be considered as 'sustainable' it should provide a better balance between economic, social and environmental aspects. Economic measures mainly consider how the building provides better value for its stakeholders. Social issues concern societal wellbeing, and environmental considerations deal with how the building optimises environmental benefits. However, these triple considerations are multifaceted and many of their sub-attributes seem qualitative and difficult to quantify. Literature reveals that sustainable buildings have the in-built ability to adjust to changing circumstances and technologies, without excessive waste and conflict (Yates, 2003; Kendall and Ando, 2005). In its simplest form, sustainable futures are ones in which the basic means of human livelihood get easier, human opportunities become richer, and nature's diversity is more sustained, and not only limited to the rich parts of the world (Holling, 2000). Literature emphasise that integrating adaptable potentials within new buildings will provide better value for clients' investments and thereby further contributing to sustainability. Twelve (12) semi structured interviews were undertaken among the construction industry professionals ( 2 architects, 5 
project contractors, 4 quantity surveyors, and a project manager), to investigate how adaptable buildings enhance sustainability. The findings are categorised into economic, environment and social considerations as indicated below, and are supported by quotations from the interviewees where relevant.

\section{Economic considerations}

Adaptable buildings enhance lifecycle value (benefits over costs) of buildings, and also provide more economic and financial benefits to its stakeholders. They are more capable of accommodating future changes that offer high flexibility and economical solutions. One interviewee remarked: 'if a building can accommodate the required function out of the existing building, then that building provides an economic return'.

Adaptable buildings reduce the whole lifecycle cost, especially when it comes to its in-use phase (maintenance and operations). In some instances the initial cost maybe high when compared with traditional maladaptive buildings as adaptable buildings consider durability/quality of materials and their energy performance. This of course create good markets for the property as tenants would like to pay less for maintenance and operations of buildings, and highly likely to retain in the same premises.

Adaptable buildings reduce the void periods during letting / marketing phase as they are almost ready to accommodate new use once planning permission is granted. With regard to lettings, another interviewee explained that 'adaptation is a more attractive option than going for a rebuild. Most occupiers of these buildings are short term occupants, but landlords who are looking to rent them will want to have continued business depending on the market demand for that area'. Supportively, another interviewee referring to the 'length and quality of lease the people sign', noted that 'a blue chip client it is more likely to get attracted to an adaptable option, than if it is a small short-term client'.

A recent interview with a project contractor who took part in Grosvenor development, Liverpool 1 noted that 'the typical model that was adopted in city centre retail developments was that the developer builds the shell and core of the building and then left to be fitted out at a later date. It depends on who they get from the retail sector to come and rent the space out and how they want it to be fitted out. For example, if Tesco (British multinational grocery and general merchandise retailer) wanted to rent a space out in this development, they will have different requirements to Waterstones (British book retailer) because of the varying requirements of the retailers. The developer will never make any money if they were very specific with the designs; they've got to be as flexible as they can. In a large scale retail development the developer will get an "anchor tenant" on board and what an anchor tenant is 
the main tenant for a developed area for this development'. This statement indicates that the new building stock has given a degree of consideration to increasing the adaptable potentials, with the hope that it will lead to significant commercial and economic benefits.

Adaptable buildings also reduce the risk on capital and can be expected faster return on investment. Therefore, investing on adaptable building is a long term profitable business. The location and the business cycles play a key role in investing on adaptable properties. Apart from all these facts, the majority of interviewees agreed that in practice all depends upon economics trumps'. Arguably, one interviewee pointed out the 'existing planning doesn't force builders to build buildings that can be changed'. 'Structural soundness', 'fit for purpose' (suitable location), and 'flexibility within the internal space' are mandatory criteria to be considered before adapting the building to subsequent uses.

\section{Environmental considerations}

Environmental sustainability considerations are given a high priority in the UK Government procurement strategies. One of the architects noted: 'ideally adaptable buildings are designed with an element of durability in them, flexibility of layout, which provides through-life adaptable possibilities to its users'. This helps conversion process much easier and cheaper than the major refurbishments or renewals, and leads towards a lower demolition and landfill waste. Bypassing wasteful processes of demolition and major refurbishments improves the environmental benefits and minimise the taxes (eg. landfill tax, climate change levies). On the other hand, the attention on low embodied and operational carbon contents of buildings are highly encouraged within the Construction 2025 strategy. An introduction of green certificates (eg. BREEAM/LEED) and energy ratings for buildings (eg. EPC - Energy Performance Certificate), are also a value addition to buildings. With regard to a variety of sustainable features associated with adaptable buildings, majority of interviewees agreed that 'adaptable buildings tick the boxes for green credentials, and this of course improve the market recognition of these buildings'.

Quality of materials is a major consideration in adaptable buildings as some materials age very quickly. As adaptable buildings promote opportunities for refitability, they provide high flexibility to replace the aged material/component with a new one, depending on the type of adaptation required. High quality materials may be expensive in terms of initial cost but may be cheaper to maintain. However one of the four quantity surveyors strongly emphasised: 'environmental aspects are only driven by money. People will include the environmental aspects if there is money behind it, if they can save some money out of it'. 


\section{Social considerations}

Social sustainability considerations determine the quality and comfort of people and their relationship to their environment. The adaptable features integrated within a building optimise the building use or in other way minimises the functional obsolescence. Having analysed the societal considerations of adaptable buildings, one interviewee noted: 'if a building does not fit for purpose, it will remain vacant until it finds the correct use. This can be an attractive target for crime-related activities as well as creating high repair and maintenance costs to the owners'. This will destroy the social security and well-being. Therefore, integrating potential adaptable features within buildings provided win-win solutions to both its stakeholders and the society.

The empirical evidence presented above, proved the ability of adaptable buildings to respond to the built environment changes by saving non-renewable resources, minimising waste production, ease of retrofit etc. On the other hand, a building that is 'unfit for purpose' leads to being redundant in its functional tenure. In this light, either design for adaptations or design for short lifespans can be considered. However, design for short life is not always appreciated in the sustainable agenda as many building components are economical in long structural lifespans. Majority of the interviewees did not agree with the notion of design for short lifecycles. One interviewee pointed out: 'short term stuff, short term thinking can be harmful to the environment'. Supportively, another interviewee noted 'a long life cycle means that you have to consider the environment much more, so I think long life cycle is better environmentally and socially. Economically sometimes I suppose the short lifecycles might be a quick fix and people could make some money quickly, but I am against that'.

The challenges of 'design for future' were also acknowledged by the interviewees. The future-proofing endeavour seems difficult and risky because the decisions taken today need to be justifiable tomorrow, and perhaps these decisions may only vaguely fit tomorrow's requirements. One of project contractors emphasised: 'designing for adaptation is tricky because, it means people will have to predict the future which is tricky'. In this regard, spending too much over budget for an uncertain target could also be considered a waste.

\section{Discussion}

Sustainability is one of the significant considerations in the built environment. The growing attention in the government policies and the higher level strategies further necessitates focusing on sustainability. Literature indicated that the built environment is faced with a 
number of challenges, and adaptability is recommended as an ideal solution to respond some of those challenges. Benefits such as cost savings are already reported in the literature. Different strategies and parameters for adaptability in buildings are reported. Ability to change use (convertibility) is one of them.

The case study focused on a selected cluster from the Liverpool city centre. The Morphological Analysis revealed that $60 \%-70 \%$ of the buildings of the selected cluster have gone through a process of adaptation during a period of over 100 years. It is more in the form of an evolved adaptation rather than a planned one. Out of the strategies for building adaptation, 'change of use' is the specific form of adaptation observed within this cluster. Furthermore, $10 \%-12 \%$ of buildings in the selected cluster had changed their use every 6 years during the period of last 25 years, thereby revealing an increase in the rate of change of use.

Planning policies promoting the city as a commercial hub, incentives in the form of external funding, realisation of the city as an international mobility hub and government support directly as part of the regeneration of deprived areas were the main reasons behind this change of use, which has resulted in transformation of residential and social buildings spaces to commercial spaces. The most successful places are able to adapt to changing circumstances, places need to adapt at every scale. A household makes different demands on a house as children are born and grow up, the towns and cities as a whole have to adapt as industries rise and decline and as the demand for housing and the nature of the workplace changes. A new development should firstly consider the re-use of existing buildings where they make a positive contribution to the street and when new buildings are proposed good urban design that provides for adaptability can help ensure that changing needs are met and can help to avoid obsolescence, dereliction and the need for comprehensive development. And then it goes on to state what the actual policy is (eg. the fifth policy of urban design adaptability). A development proposal should be designed for flexibility with the future in mind and should provide opportunities to adapt to changing needs of the users and also have flexible layouts which allow for the greatest variety of possible future uses to be accommodated.

Sustainability can be discussed in terms of economic, environmental and social considerations. The interview findings provided an overall acknowledgment that adaptable buildings contribute to sustainability. Economic considerations seem to be the main driver, followed by environmental and social considerations. Economic benefits were strongly emphasised for the owner occupied and well as rentable buildings. Increased rate of return from investment and reduced whole life cycle costs were the main attractions. Energy 
efficiency over the life span of the building, reduction of waste, recognition for the building in terms of green credentials etc., were the main environmental considerations. It is noteworthy that the environmental considerations were also thoughts as possible only if there are sufficient economic / financial benefits. The social considerations were indicated mainly through highlighting the risks of non-adaptation. Ability to maintain the user satisfaction / attraction can help to maintain continued occupancy. Non-occupation of buildings leads to the locations becoming prone to crime. Prevention of crime through continued occupation due to adaptation of the buildings is seen as a major social benefit.

\section{Conclusions}

Exploring the potential contribution of adaptable buildings towards the sustainability of the built environment was the purpose of this research. Literature review, a case study focused on a selected cluster of the Liverpool city centre, and semi-structured interviews, were the research methods adopted. The findings have established the positive contribution of adaptable buildings towards achieving sustainability. This has been evidenced in terms of economic, environmental and social considerations. It is worth noting that the form of adaptation has been through 'change of use', and it has occurred in an evolving manner over a period of more than 100 years, rather than as a planned one. Economic considerations have been highlighted as the key driver for making buildings adaptable.

Considering the strong emphasis placed by the UK government on sustainability, this research further strengthens the case for incorporating adaptability as a criterion for evaluating building designs and urban regeneration schemes. However, the construction industry does not possess a clear track record of considering building reusability in a proactive manner, especially during the design phase. This highlights the need for the industry to focus more on this aspect as it develops future strategies. Change of use was the evident adaptable feature in this research. Other adaptable features such as scalability, movability etc. (Adaptable Futures, 2012), can be considered in similar research investigations of this nature.

The sustainable benefits from adaptable buildings would be the motivation factor to promote adaptable buildings within the UK construction industry. The key economic benefits such as better value for clients' investments, income potentials, tax concessions, and a remedy for redundancy are greatly acknowledged. However, given the complex stakeholder engagement, information intensity, process complexities etc., it is necessary to develop an appropriate environment which facilitates the development of adaptable buildings. Even 
though the exogenous demand arise for implementing adaptable strategies in the built environment, existing planning and policy issues appear to be a major constraint to designing buildings for potential adaptations. For example, different sustainability parameters may receive varying levels of priority at various points (such as the higher priority given for the need to comply with a certain percentage of energy being obtained from renewable sources), thereby losing the focus on ensuring and enhancing the adaptability potentials. This is a key consideration for developing and implementing planning approval procedures.

It is worth investigating how existing design practices can be improved to encourage adaptable potential of buildings. Furthermore, research studies on how adaptability can be empowered in terms of incentives, processes, stakeholder engagement and technology leverage (especially the rapidly developing information technology enabled tools such as Building Information Modelling - BIM), and whole life cost and value considerations, will help to improve the adaptability of buildings and its contribution to the sustainability of the built environment.

\section{References}

3DReid. 2006. Multispace: Adaptable Building Design Concept, (2006), Reid Architecture, London. Case Study edn. London: Reid Architecture.

Adaptable Futures. 2012. [Homepage of Adaptable Futures], [Online]. Available: http://www.adaptablefutures.com [02/05, 2014].

Adeyeye, K., Bouchlaghem, D. and Pasquire, C. 2010. A conceptual framework for hybrid building projects. Facilities, 28(7/8), pp. 358-370.

Arge, K. 2005. Adaptable office buildings: theory and practice. Facilities, 23(3/4), pp. 119127.

Ball, R. 1999. Developers, regeneration and sustainability issues in the reuse of vacant buildings. Building Research and Information, 27(3), Pp. 140-148.

Barnard, R. 1970. 'Community action in a twilight zone', RIBA Journal, P. 446., 
Beisi, J. 1993. Adaptable housing or adaptable people? Experience in Switzerland gives a new answer to the questions of housing adaptability. Arch. \& Comport. / Arch. Behav., 11(2), Pp. 139-162.

Blakstad, S.H. 2001. A strategic approach to adaptability in office buildings, Trondheim, Norwegian University of Science and Technology.

Brand, S. 1994. How buildings learn - What happens after they're built. USA: Penguin.

Conejos, S., Langston, C., and Smith, J. 2014. Designing for better building adaptability: A comparison of $<\mathrm{i}>$ adaptSTAR</i> and ARP models. Habitat International, Vol 41, Pp. 85-91.

Couch, C., 2003. City of change and challenge- Urban planning and regeneration in Liverpool. UK: Ashgate Publishing Ltd.

Daramola-Martin, A. 2009. Liverpool one and the transformation of a city: Place branding, marketing, and the catalytic effects of regeneration and culture on repositioning Liverpool, Place Branding and Public Diplomacy, Vol 5 (4), Pp. 301-311.

Davison, N., Gibb, A.G., Austin, S.A. and Goodier, C.I. 2006. The multispace adaptable building concept and its extension into mass customisation, F. Scheublin and A. Pronk, eds. In: Proceedings of the Joint CIB, IASS International Conference on Adaptability in Design and Construction (Adaptables2006), 3rd - 5th July 2006, TU/e Delft University of Technology, The Netherlands, Pp. $12.7-12.13$.

Department for Business, Enterprise and Regulatory Reform, 2008. Strategy for sustainable construction, HM Government, London, UK.

Douglas, J. 2006. Building adaptation. 2nd edn. UK: Butterworth-Heinemann Ltd.

Ellingham, I. and Fawcett, W. 2006. New generation whole life costing: property and construction decision making under uncertainty. 1st edn. Oxon: Taylor and Francis.

Farrell, T. 1979. A designer's approach to rehabilitation. In: T. Markus, ed, Building conversion and rehabilitation: Designing for change in building use. 1st edn. London, UK: NEWNES - Butterworths, pp. 59-82.

Flanagan, R. and Tate, B. 1997. Cost control in building design. 1st edn. London, UK: Blackwell Science.

Ford, D.N. and Garvin, M.J. 2010. Barriers to real options adoption and use in architecture, engineering, and construction project management practice. In: H.B. Nembhard and M. 
Aktan, eds, Real options in engineering design, operations, and management. 1st edn. USA: CRC Press, Pp. 53-73.

Gann, D.M. and Barlow, J. 1996. Flexibility in building use: the technical feasibility of converting redundant offices into flats. Construction Management and Economics, Vol 14(1), Pp. 55-66.

Geraedts, R. 2008. Design for change flexibility key performance indicators, Industrialised, integrated and intelligent construction, 14th May 2008, Loughborough University, UK.

Gijsbers, R., Cox, M.G.D.M., Haas, T.C.A.D., Kok, P. and Hulsbergen, H. 2009. Development of a membrane roofing system with integrated climate control for community shelters. A. Dobbelsteen, M. Dorst and A. Timmeren, eds. In: Smart and sustainable built environments, 15-19 June 2009, TU/e Delft University of Technology, The Netherlands, Pp. $1-8$.

Gregory, C. 2006. Loose fit. L25230-ON1MA-CG240206. London, UK: 3DReid.

Groak, S. 1992. The Idea of Building: Thought and Action in the Design and Production of Buildings, London, UK: E \& FN Spon.

Habraken, N.J. 1980. Design for Adaptability, Change and User Participation. In Housing: Process and Physical Form. Linda Safran (ed). Philadelphia: Aga Khan Award for Architecture, Pp. 23-29.

Heath, T. 2001. Adaptive re-use of offices for residential use: The experience of London and Toronto. Cities, Vol 18(3), Pp. 173-184.

Henehan, D. and Woodson, R.D. 2003. Building change of use: Renovating, adapting and altering commercial, institutional and industrial properties. 1st edn. New York: McGraw-Hill Professional.

HM Government. 2013. Construction 2025: Industrial Strategy: government and industry in partnership, available online: https://www.gov.uk/government/publications/construction-2025strategy, accessed on $2^{\text {nd }}$ July 2015.

Holling, C. S. 2000. Theories for sustainable futures. Conservation Ecology 4(2): P.7. Available online: http://www.consecol.org/vol4/iss2/art7, accessed on $4^{\text {th }}$ Mar 2014.

Itard, L and Klunder, G. 2007. Comparing environmental impacts of renovated housing stock with new construction. Building Research \& Information, Vol 35(3). Pp.252 - 267. 
Kalita, N. 2006. Cost models: Business parks. Building, 24.

Kapustyan, E. 1974. Standard requirements and multi-storey housing design. Building Research and Information, 2(5), Pp. 280-285.

Kendall, S. 1999. Open building: an approach to sustainable architecture. Journal of Urban Technology, 6(3), Pp. 1-16.

Kendall, S. 2003. An open building strategy for converting obsolete office buildings to residential uses, 22nd - 24th July 2003, International Lean Construction Institute, Pp.1-12.

Kendall, S. and Ando, M. 2005. Theory and methods in support of adaptable buildings, Action for Sustainability - The 2005 World Sustainable Building Conference, Tokyo, Japan, $27^{\text {th }}-29^{\text {th }}$ September 2005.

Keymer, M.A. 2000. Design strategies for new and renovation construction that increase the capacity of buildings to accommodate change, Unpublished thesis, MIT, Cambridge, USA.

Kincaid, D. 2000. Adaptability potentials for buildings and infrastructure in sustainable cities. Facilities, Vol 18(3/4), Pp. 155-161.

Kincaid, D. 2002. Adapting building for changing uses - Guidelines for change of use refurbishments. 1st edn. London, UK: Spon Press.

Kohler, N. and Hassler, U. 2002. The building stock as a research object. Building Research and Information, Vol 30(4), Pp. 226-236.

Kronenburg, R. 2007. Flexible: Architecture that responds to change. 1st edn. London, UK: Laurence King Publishing.

Larssen, A.K. and Bjorbery, S. 2004. Users demand for functionality and adaptability of buildings - a model and a tool for evaluation of buildings, Proceedings of the CIBW70 2004 Hong Kong International Symposium, Kowloon Shangri-La Hotel, Hong Kong. 7th - 8th December 2004, Pp. 167-176.

Latham, D. 2000. Creative re-use of buildings - principles and practice, Dorset, UK: Donhead Publishing Ltd.

Lau, R.M. 2001. Economic considerations for tall multi-use buildings. CTBUH Review, Vol 1(2), Pp. 32-35.

Nutt, B. 2000. Four competing futures for facility management. Facilities, Vol 18(3/4), Pp. 124 -132 . 
Pati, D., Harvey, T. and Cason, C. 2008. Inpatient unit flexibility. Environment and Behaviour, 40(2), Pp. 205-232.

Ratcliffe, J. and Stubbs, M. 1996. Urban Planning and Real Estate Development. 1st edn. London, UK: UCL Press.

Rawlinson, S. and Harrison, I. 2009. Cost model office refurbishment. Building Magazine, Vol 10(3), Pp. 48-53.

Remoy, H.T. and Voordt, T.J.M. 2007. A new life: Conversion of vacant office buildings into housing. Facilities, Vol 25(3/4), Pp. 88-103.

Ren, L., Shih, L., and McKercher, B. 2014. Revitalization of industrial buildings into hotels: Anatomy of a policy failure. International Journal of Hospitality Management, Vol 42, Pp. 3238.

Ritcher, U. and Laubach, A. 2005. The adaptable tall building. Lacer No 5. Germany: available at: http://aspdin.wifa.uni-leipzig.de/institut/lacer/lacer05//05_10.pdf.

Robertson, B. and Shibar, V. 2002. The Adaptive Enterprise: IT infrastructure strategies to manage, change, and enable growth. 1st edn. Boston, USA: Intel Press.

Russell, P. and Moffatt, S. 2001. Assessing buildings for adaptability: IEA Annex 31 Energyrelated environmental impact of buildings. Germany: http://annex31.wiwi.unikarlsruhe.de/pdf.

Saari, A. and Heikkila, P. 2008. Building flexibility management. The Open Construction and Building Technology Journal, Vol 2(1), Pp. 239-242.

Schneider, T. and Till, J. 2005. Flexible Housing: Opportunities and Limits. Architectural Research Quarterly, Vol 9(2), Pp. 157-166.

Sheffer, D.A. and Levitt, R.E. 2010. How industry structure retards diffusion of innovations in construction: Challenges and Opportunities. Working paper 59. UK: Collaboratory for Research on Global Projects.

Shipley, R., Utz, S., Parsons, M. 2006. 'Does Adaptive reuse Pay? A Study of the Business of Building Renovation in Ontario, Canada', International Journal of Heritage Studies Vol. 12(6), Pp. 505-520 
Silverthorne, T. 2006. What constitutes success in brownfield redevelopment? In: C.A. Brebbia and U. Mander, eds, Brownfields III: Prevention, assessment, rehabilitation and development of brownfield sites. 1st edn. Boston, UK: WIT Press, Pp. 39-49.

Slaughter, E.S. 2000. Implementation of construction innovations. Building Research and Information, Vol 28(1), Pp. 2-17.

Slaughter, E.S. 2001. Design strategies to increase building flexibility. Building Research and Information, Vol 29(3), Pp. 208-217.

Thomsen, A. and Flier, K. 2009. Replacement or renovation of dwellings: The relevance of a more sustainable approach. Building Research and Information, Vol 37(5), Pp. 649-659.

Verweij, S. and Poelman, W.A. 2006. Evaluation of flexibility options in different housing projects, F. Scheublin and A. Pronk, eds In: Proceedings of the Joint CIB, IASS International Conference on Adaptability in Design and Construction (Adaptables2006), 3rd - 5th July 2006, TU/e Delft University of Technology, The Netherlands, Pp. 38-42.

Yates, A. 2003, Sustainable buildings: benefits for constructors, Building Research Establishment, IP 13/03, Part 4, London, UK.

Yates, A. 2003. Sustainable buildings: benefits for designers, Building Research Establishment, IP 13/03, Part 2, London, UK.

Yates, A. 2003. Sustainable buildings: benefits for investors and developers, Building Research Establishment, IP 13/03, Part 3, London, UK.

Yates, A. 2003. Sustainable buildings: benefits for occupiers, Building Research Establishment, IP 13/03, Part 1, London, UK. 